\title{
DEVELOPING A MOBILE APPLICATION FOR SMART REAL ESTATE INFORMATION
}

\author{
A. C. Aydinoglu, ${ }^{1 *}$, R. Bovkir ${ }^{1}$ \\ ${ }^{1}$ Dept. of Geomatic Engineering, Gebze Technical University, Gebze, Kocaeli - aydinoglu; rbovkir @ gtu.edu.tr
}

Commission VI, WG VI/4

KEYWORDS: MobileGIS, Real Estate Valuation, Mobile Application, Smart City, Machine Learning.

\begin{abstract}
:
Successful land information management is an important issue for governments in regards to sustainable development. Reliable and comprehensive data about land and all related factors are essential for effective land policies. Various land related legal applications such as planning, taxation, property management, mortgage, and real estate investments require interoperable, extensive and realistic information about the land and real property. GIS provides greater insight into land by its capability to advance geographic analysis in different aspects. The statistical analysis capabilities of GIS increase the efficiency and accuracy of the evaluations related to land and real estate. Along with the developments of information and communication technologies, modern GIS technologies can handle large and complex data. Web-based and mobile GIS technologies provide the capability of operating and sharing local data and provide geographic analysis tools to users via the web. In this way, various mobile GIS applications can be developed in many different application areas. In this study, a mobile application titled as Smart Real Estate was developed for presenting urban real estate characteristics in different thematic groups by analysing data in different formats coming from different sources.
\end{abstract}

\section{INTRODUCTION}

Comprehensive and successful management of land information is essential for governments in achieving sustainable development and progress. A successful land management policy needs reliable, interoperable and extensive information about the land and real estate in every aspect (FIG, 2002). Legal practices such as planning, taxation, property management, mortgage and market capitalisation, real estate investments and funds need comprehensive and reliable information about the land and real property (Deininger and Selod, 2012; Bovkir and Aydinoglu, 2018). Therefore, valuation of land and accurate determination real estate speculations has great importance in terms of conducting planned urbanization, selection of settlement and investment areas, taxation, and land arrangement (Deininger 2004; Dyca 2018; Aydinoglu et al., 2020). In this regard, it is highly important to determine factors affecting real estate values for successful and effective land management (Bovkir and Aydinoglu 2018).

Geographic information system (GIS) technologies promote effective land and real estate management by providing greater insight into land in different aspects (Longley et al., 2005; (Shcherbina et al., 2010; Zivkovic and Dordevic, 2016). Because data alone is not enough for better decision making, it should be analysed effectively with a wider perspective. The geographic analysis tools of GISs increase the efficiency and accuracy of land and real property valuation processes (Longley et al., 1994; Wyatt, 1997; Zeng and Zhou, 2001; Yang et al., 2015; Aydinoglu et al., 2020). GIS can be used in various application areas to analyse different characteristics of the physical, topographical and social environment because of its capability of processing big and different structured geographic data. In this way, a better understanding provided to the user in order to analyse land dynamics and make successful decisions about real estates.
Modern GIS technologies use digital information generated by various digital technologies and contain larger, complex, and continuously increasing geographic data (Matney et al., 2019). The fact that such large data structures can be active in a global network and online wherever there is the internet. WebGIS allows to operate and distribute the local data, to provide geoanalytics tools to the users on the web, to browse and update the different data layers in a web application and all these capabilities ensure the MobileGIS applications to use on the mobile devices (Soomro et al., 1999; Khasha et al., 2018). With the integration of big data, cloud computing and WebGIS, the presentation and analysis of geographic data in MobileGIS applications can be faster and the presentation in this environment can be more optimized and uninterrupted. MobileGIS are used in many different applications areas such as monitoring health (Tsou, 2004; Hsueh-Ting et al.,2006; Klasnja and Pratt, 2012; Khasha et al., 2018), environmental mapping and monitoring (Arrington et al., 2017; Guilbaud and Guilbaud, 2017; Lindgren, 2017; Nowak et al., 2020); urban planning (Jurado et al., 2019; Kim et al., 2019; Munoz et al., 2019) and mobility (Bandara et al., 2014; Gharbi and Haddidi, 2020).

In this study, it is aimed to develop a mobile application for demonstrating urban real estate characteristics for different thematic groups by analysing data in different formats coming from various public information sources. In the smart city concept, it is important to use open public information and serve them to the citizens via smart applications. In this aspect, firstly data provided from different public resources for the study area Pendik, thematic surfaces were produced by using geographic analysis in a GIS environment. After the creation of the thematic surfaces for each criterion, these surfaces were evaluated by using fuzzy logic with the help of GIS analysing tools. In this way, objective and comprehensive evaluations

\footnotetext{
* Corresponding author
} 
about urban land and real estates can be performed. Secondly, A mobile application titled as Smart Real Estate was developed in Android Studio development environment. Finally, fuzzy surfaces representing thematic values of real estates were served via web services on the application to be visualized.

\section{PROCESSING AND ANALYSING DATASETS FOR THE MOBILE APPLICATION}

Parameters affecting land and real estate are very diverse and highly complex. Therefore, in order to perform objective and accurate evaluations, all parameters related to land and property should be considered and taken into consideration (Bovkir and Aydinoglu, 2018). Factors affecting land value are grouped into six thematic groups in which have integrity based on the national and international standards, regulations and academic studies. The thematic factor groups are named as environmental factors, public services, cultural factors, transportation, utilisation, socioeconomic factors which have a total of 20 criteria in Table 1 (Aydinoglu et.al., 2019).

- Environmental factors include data related to the locational features of real estate such as distances to industry, infrastructure, green spaces and cemeteries.

- Public services include data related to the distances to public facilities such as educational facilities, religious facilities, healthcare centres and public utilities.

- Cultural factors include the centres related to cultural and leisure activities such as cultural (cinema, theatre, art gallery, library etc.) and shopping centres.

- Transportation includes data related to public transportation such as the distances to main roads, highways, bus and metro stations, airports and parking areas.

- Utilization includes data related to the utilisation of the land which real estates are located such as slope and aspect.

- Socio-economic factors include data related to the socioeconomic status of real estate owners and neighbourhoods such as population density and university graduate rate.

Geographic characteristics of each criterion in thematic groups were produced and optimised by following the data analysing processes for the study area:

- Creation of POIs: Polygon data such as education, health, cultural, religious, infrastructure facilities; parking lots, industrial areas, public institutes, shopping centres, cemeteries, green spaces and airport has been converted into Point data (POIs).

- Generation Thematic Surfaces: In order to obtain pixel-based thematic surfaces, analyses such as slope, aspect, density and Euclidean distance was performed.

-- Slope Analysis: The slope surface was generated in raster format in per cent or degrees by showing the slope values calculated over the numerical terrain model at desired intervals in a GIS environment.

-- Aspect Analysis: Aspect refers to the compass direction of the slope in physical geology. North is represented as 0, East is 90 , South is 180 and West is 270 degrees. Smooth areas are represented as -1 . The aspect surface was produced in a GIS environment.

-- Density Analysis: Density surfaces show where a point or a line increases and clusters. Population density and university graduates rate belonging to the study area were produced with point density in the GIS environment.
-- Euclidean Distance (ED) Analysis: ED analysis is a distancebased calculation which calculates the distances from each pixel in the raster to the closest target source with the Euclidean calculation. The thematic distance surfaces (educational, health, cultural, religious, cemetery, infrastructure, shopping centres, airport, parking, industry, green areas) and distances to metro and bus stations, main roads and highways were produced with Euclidean distance analysis in a GIS environment.

Criteria in Table 1 were evaluated with fuzzy logic in a GIS environment. According to the characteristics for each criterion, fuzzy membership functions were applied for each criterion. In this way, due to their memberships, each pixel in the raster surfaces has pixel values ranging from 0 to 1 . Thereafter, fuzzy overlay surfaces for each thematic group were created with AND and OR functions. Table 1 lists the thematic groups with their sub-criteria, the type of fuzzy membership and overlay function with their critical point $(\mathrm{t})$.

\begin{tabular}{|c|c|c|c|c|}
\hline $\begin{array}{l}\text { Thematic } \\
\text { Group }\end{array}$ & Sub-criteria & $\mathbf{t}^{*}$ & $\begin{array}{l}\text { Membership } \\
\text { function }\end{array}$ & $\begin{array}{l}\text { Overlay } \\
\text { function }\end{array}$ \\
\hline \multirow{4}{*}{$\begin{array}{l}\text { Environmental } \\
\text { factors }\end{array}$} & Distance from industry $(\mathrm{m})$ & 800 & Sigmoid & \multirow{4}{*}{ AND } \\
\hline & $\begin{array}{l}\text { Distance from } \\
\text { infrastructure }(\mathrm{m})\end{array}$ & 800 & Sigmoid & \\
\hline & $\begin{array}{l}\text { Distance from green space } \\
(\mathrm{m})\end{array}$ & 600 & Inverted sigmoid & \\
\hline & $\begin{array}{l}\text { Distance from cemeteries } \\
\qquad(\mathrm{m})\end{array}$ & 800 & Sigmoid & \\
\hline \multirow{4}{*}{ Public services } & $\begin{array}{l}\text { Distance from education } \\
\qquad(\mathrm{m})\end{array}$ & 800 & Inverted sigmoid & \multirow{4}{*}{ AND } \\
\hline & $\begin{array}{l}\text { Distance from religious } \\
\text { facilities }(\mathrm{m})\end{array}$ & 800 & Inverted sigmoid & \\
\hline & $\begin{array}{l}\text { Distance from healthcare } \\
\qquad(\mathrm{m})\end{array}$ & 600 & Inverted sigmoid & \\
\hline & $\begin{array}{c}\text { Distance from public } \\
\text { utilities }(\mathrm{m})\end{array}$ & 800 & Inverted sigmoid & \\
\hline \multirow{2}{*}{ Cultural factors } & $\begin{array}{l}\text { Distance from cultural } \\
\text { centres }(\mathrm{m})\end{array}$ & 800 & Inverted sigmoid & \multirow{2}{*}{ AND } \\
\hline & $\begin{array}{c}\text { Distance from shopping } \\
\text { centres }(\mathrm{m})\end{array}$ & 800 & Inverted sigmoid & \\
\hline \multirow{6}{*}{ Transportation } & $\begin{array}{l}\text { Distance from highways } \\
\qquad(\mathrm{m})\end{array}$ & 2000 & Inverted sigmoid & \multirow{6}{*}{ OR } \\
\hline & $\begin{array}{l}\text { Distance from main-roads } \\
\qquad(\mathrm{m})\end{array}$ & 100 & Inverted sigmoid & \\
\hline & $\begin{array}{l}\text { Distance from bus stops } \\
(\mathrm{m})\end{array}$ & 400 & Inverted sigmoid & \\
\hline & $\begin{array}{l}\text { Distance from metro } \\
\text { stations }(\mathrm{m})\end{array}$ & 800 & Inverted sigmoid & \\
\hline & $\begin{array}{l}\text { Distance from the airport } \\
\qquad(\mathrm{m})\end{array}$ & 3000 & Inverted sigmoid & \\
\hline & Distance from parking (m) & 1000 & Inverted sigmoid & \\
\hline \multirow{2}{*}{ Utilization } & Slope (degrees) & 20 & $\begin{array}{l}\text { Monotonically } \\
\text { decreasing linear }\end{array}$ & \multirow{2}{*}{ AND } \\
\hline & Aspect (degrees) & - & $\begin{array}{l}\text { Symmetric } \\
\text { Gaussian }\end{array}$ & \\
\hline \multirow{2}{*}{$\begin{array}{l}\text { Socio-economic } \\
\text { factors }\end{array}$} & $\begin{array}{l}\text { Population density (low-to- } \\
\text { high) }\end{array}$ & - & $\begin{array}{l}\text { Monotonically } \\
\text { decreasing linear }\end{array}$ & \multirow{2}{*}{ AND } \\
\hline & $\begin{array}{l}\text { University graduate rate } \\
\text { (low-to-high) }\end{array}$ & - & $\begin{array}{l}\text { Monotonically } \\
\text { decreasing linear }\end{array}$ & \\
\hline
\end{tabular}

Table 1 . The valuation criteria with fuzzy membership function

In fuzzy logic theory developed by Zadeh (1965) each element graded between 0 and 1 (Zadeh, 1965). An element of a fuzzy set can be a full member (100\% membership) and gets the value of 1 ; no member $(\% 0)$ and gets a value of 0 or a partial member (between $0 \%$ and $100 \%$ membership) and gets a value between 0-1 (Nedeljkovic, 2006). It means, as in classical theory, the values of the elements are not limited to only two values 0 and 
1. The shape of the membership function of an element differs related to the requirements of the application. It can be linear/non-linear, continuous/ non-continuous, symmetrical/ non-symmetrical such as Linear, Gaussian, Sigmoid and Inverted sigmoid.

Fuzzy set operators are used for the evaluations of the fuzzy rules. Most common and used fuzzy operators in GIS are AND (Intersection) and OR (Union) operators. As an example, Environmental factors raster surface representing the locational features of the real estate were created by using distance surfaces in Table 1 as distances to industry, infrastructure, green spaces and cemeteries. Firstly, fuzzy memberships were determined with ideal accessibility distances to apply for fuzzy memberships as listed in Table 1. Then, fuzzy surfaces were overlaid by the fuzzy AND operator (Figure 1).

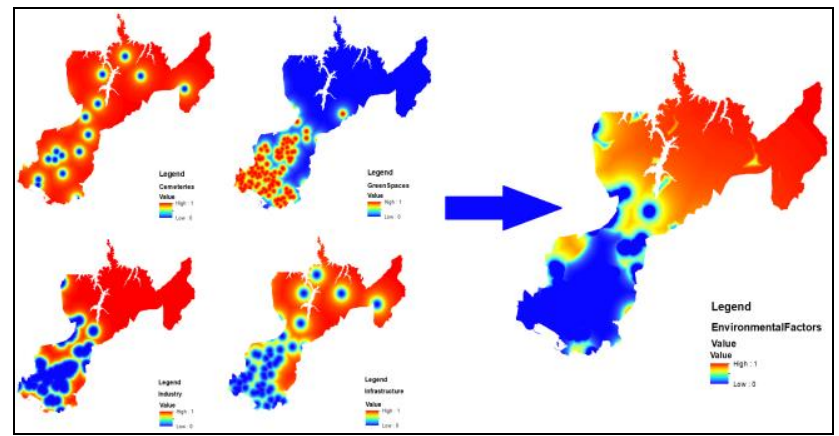

Figure 1. Creation of the Fuzzy Surface of Environmental Factors

\section{DEVELOPING THE SMART REAL ESTATE MOBILE APPLICATION}

The Smart Real Estate mobile application has been developed to ensure the interoperability between different heterogeneous geographic datasets and services. It uses the output data produced by the geo-analysis tools and machine learning algorithms from different data sources between applications. The developed mobile app can be considered as a template for similar applications openly and freely. The Smart Real Estate application enables the open service of geographic data sets in PostgreSQL and PostGIS databases with web services and the presentation of data analysis results to the mobile user in the Android environment. Thus, the user can access the pre-defined real estate ads in specified locations with the desired criteria. Also, it allows serving geo-data sets processed with geoanalytic tools via web services. In this way, valuation results in the selected locations can be provided to the decision-makers and citizens freely. The architecture diagram of the Smart Real Estate mobile application is presented in Figure 2.

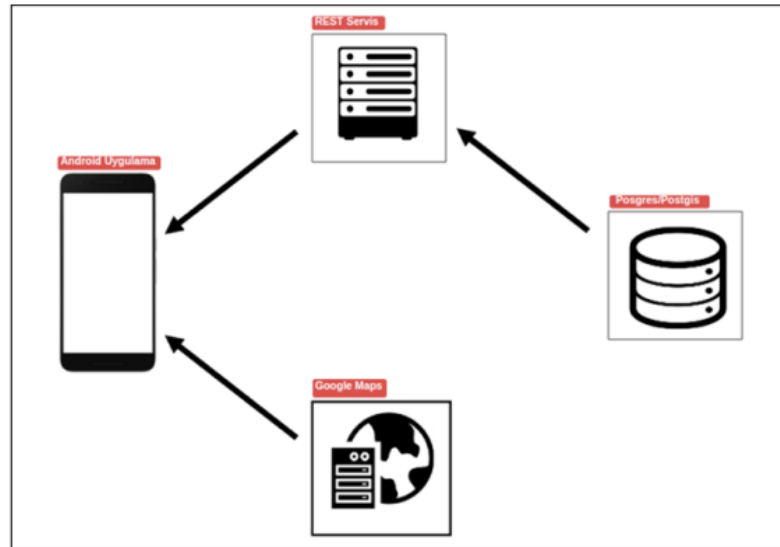

Figure 2. Architecture diagram of the Smart Real Estate mobile application

The Smart Real Estate application was developed on the Android Studio development environment with Java programming language. It supports Lollipop (API Level 22) and Pie (API Level 28) operating system versions. In this way, it is available on $80.2 \%$ of the entire mobile devices' ecosystem. As the map component, Google Maps SDK for Android was used. In addition to the map bases, it provides the needed mapping features with geocoding and map services. PostGIS extension provides storage, processing and query capabilities of both vector and raster data with the help of open-sourced QGIS Desktop.

REST is a data transfer method used in service-oriented architectural software which enables quick and easy communication between client and server. In the developed application, REST web service was developed for the needed data and functionality. It provides capabilities such as listing, filtering, and calculation of real estate values. For the service, JAX-RS (Java API for RESTful Web Services) specification offered by Java EE was used and open-source Jersey framework was preferred. REST service was published on open source and free application server Jetty and Netbeans was preferred as the development environment (Figure 3).

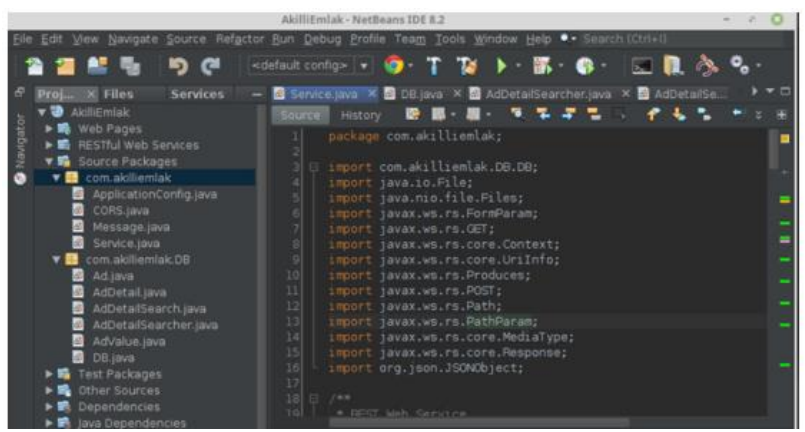

Figure 3. Screenshot of the Netbeans development environment 


\section{USING SMART REAL ESTATE APPLICATION}

The splash screen of the Smart Real Estate application is shown in Figure 4. "Address Search" function placed on the main screen (Figure 4-mid) allows the user to enter free text or select a specific location in order to focus on the map. At this stage, geocoding operations are carried out on the API provided by Google. Also, street view and satellite images provided from Google can be used as a base map. With the "Location" function at the bottom right of the main screen (Figure 4-mid) users can see their location on the map. Thus, users can separate the ads in their surroundings from the others while choosing between all ads. The positions of the ads are not text-based in the form of $X$ and $\mathrm{Y}$ and stored directly in the table with the geometry in PostgreSQL with PostGIS plug-in. With this approach, it has a structure that will allow spatial analysis in the mobile application. "Refresh" function at the bottom right of the main screen (Figure 4-mid) allows the user to reload the real estate ads provided through the adList Endpoint in the REST web service REST service in JSON format (Figure 4-right)

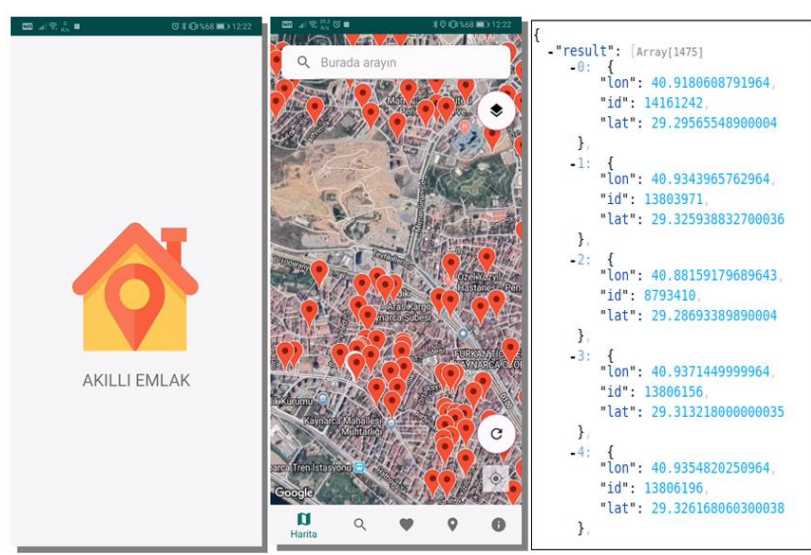

Figure 4. Smart Real Estate mobile app splash screen (left); map screen (mid) and adList Endpoint result JSON data (right)

"Real Estate Search" enables the user to access the filter screen and to search the desired criteria. A total of 12 criteria which are the type of real estates such as apartment, detached house, duplex apartment etc., the seller (realtor or owner), the price range, area, elevator, status of real estates such as newly built, fist hand or specified year range, the number of the rooms, the floor number, within a housing estate, availability of the security and parking site and type of the heater system from top to bottom can be searched synchronically (Figure 5-left). "Land Evaluation" is the most important function that distinguishes the Smart Real Estate application from its peers. With this function, specified locations can be evaluated with thematic scorings by using geo-data services produced from geo-analytic tools. This process is performed by the adValue Endpoint on the REST service (Figure 5-mid). When the value of the current real estate is calculated with the data collected from the services, value bar graphics are produced in addition to real estate information (Figure 5-right).

The datasets and raster surfaces representing the criteria in Table 1 produced as a result of the geo-analytics were served through REST services. Smart Real Estate application uses these pixel values and it presents each thematic criterion and groups generated from fuzzy logic analyses via scoring as a percentage (\%). In Figure 5-right, 12 of the 25 thematic scorings about the specified address by the user are presented along with percentiles in bar graphics. According to the real estate in the specified address as an example, scorings shows the availability of the education $(85 \%)$, green space $(82 \%)$, religious $(100 \%)$ and health $(87 \%)$ services are high; the availability of the public $(34 \%)$ and cultural (14\%) facilities, bus stops $(20 \%)$, industry $(0 \%)$, utilization characteristics $(4 \%)$ and shopping centres $(14 \%)$ are low and university graduation rate $(56 \%)$ and population density (54\%) are medium levels.

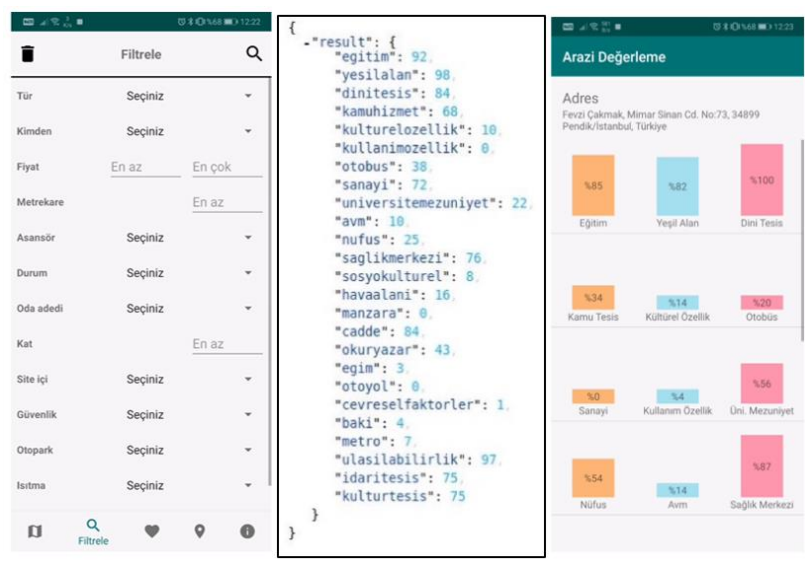

Figure 5. Real Estate Search function (left,) adValue Endpoint showing valuation records of received JSON data (mid) Value records with bar graphics (right)

\section{CONCLUSION}

Access to the objective and reliable information about urban land and real property is important in smart city concept considering the smart and transparent city management. Valuation of the urban land and real property has crucial importance in terms of planned urbanization, taxation, urban transformation and arrangements, selection of settlement and investment areas. GIS capabilities on advanced geostatistics as multi-criteria decision making give the user to process urbanrelated data from a broad perspective. As a web-based solution to operate the local data and to provide geographic analysis tools to the users on any device, MobileGIS applications are used for monitoring, analysing and mapping information in various areas within the scope of smart city applications.

Information about urban facilities can be obtained through various property applications or interactive city guides. With these applications locations of the point of interests (POIs), roads, parks, public facilities etc. can be presented. However, with these applications, complex evaluations regarding geographic locations cannot be performed. In this study, urbanrelated data coming from different public institutions in different formats analysed with advanced geographic analysis to obtain reliable and accurate evaluations about urban real estates. In the smart city concept, it is important to serve public information freely to the citizens via applications for providing better city services. In this regard, developed Smart Real Estate mobile application presents the different thematic characteristics of an urban real estate to the users for desired locations openly. Specified locations can be evaluated with thematic scorings by using from geo-analytic tools and services and presented to the users via bar graphs. 


\section{ACKNOWLEDGEMENTS}

We thank M. Selim BILGIN (M.Sc.) for his assistance in mobile application development. This research was supported by the Scientific and Technical Research Council of Turkey (TUBITAK) under project number of 116Y204.

\section{REFERENCES}

Arrington, A. B., Diemont, S. A. W., Phillips, C. T., Welty, E. Z., 2017: Demographic and landscape-level urban foraging trends in the USA derived from web and mobile app usage. $J$. Urban Econ., 3(1).

Aydinoglu, A. C., Bovkir, R., Colkesen, I., 2020: Implementing a mass valuation application on interoperable land valuation data model designed as an extension of the national GDI. Survey Review.

https://doi.org/10.1080/00396265.2020.1771967

Aydinoglu, A. C.,..., et. al., 2019. Ensuring Interoperability in Big Data Management and Analysis for Smart Cities (116Y204). TUBITAK 1001 Project Report, Kocaeli.

Bandara, R. M. P. N. S., Jayasinghe, A. B., Chemin, Y., 2014: Application of Mobile GIS for Mobility Mapping. ICC-2014 Proceedings, 91-100.

Bovkir, R. and Aydinoglu, A.C., 2018: Providing land value information from geographic data infrastructure by using fuzzy logic analysis approach. Land use policy, 78, 46-60.

Deininger, K., 2004: Land policies and land reform.Washington:World Bank.

Deininger, K., Selod, H., 2012: The Land Governance Assessment Framework: Identifying and Monitoring Good Practice in the Land Sector (Agriculture and Rural Development Series). World Bank Publications, Washington, D.C.

Dyca, B., 2018. Land value taxation and land speculation the case of São Paulo, Brazil. MSc Thesis, Erasmus University Rotterdam.

Gharbi, A. and Haddadi, S., 2020: Application of the mobile GIS for the improvement of the knowledge and the management of the road network. Applied Geomatics, 12, 23-39.

Guilbaud, C. S. and Guilbaud, T. G., 2017: Mosquito Mapper: a phone application to map urban mosquitoes. Sci. Phone Appl. Mob. Devices, 3.

Hsueh-Ting, C., Chir-Chang, H., Zhi-Hui, L., Tsai, J. J. P., 2006: A ubiquitous warning system for asthma-inducement, sensor networks, ubiquitous, and trustworthy computing. IEEE International Conference Proceedings 2006, pp. 186-191.

International Federation of Surveyors (FIG), 2002: Land Information Management for Sustainable Development of Cities Best Practice Guidelines in City-Wide Land Information Management. FIG Publications, Copenhagen, Denmark.

Jurado Rota, J., Pérez Albert, M. Y., Serrano Giné, D., 2019: Visitor monitoring in protected areas: an approach to Natura 2000 sites using Volunteered Geographic Information (VGI).
Geografisk Tidsskrift-Danish Journal of Geography, 119(1), 69-83.

Khasha, R., Sepehri, M. M, Mahdaviani, S. A, Khatibi, T., 2018: Mobile GIS-based monitoring asthma attacks based on environmental factors. Journal of Cleaner Production, $179,417-428$.

Kim, J., Thapa, B., Jang, S., 2019: GPS-based mobile exercise application: an alternative tool to assess spatio-temporal patterns of visitors' activities in a national park. J. Park Recreat. Adm., 37(1), 124-134.

Klasnja, K. and Pratt, W., 2012: Healthcare in the pocket: mapping the space of mobile-phone health interventions.

J. Biomed. Inf., 45 (1), 184-198.

Lindgren, A.N., 2017: Implementation of a Volunteered Geographic Information (VGI) Mobile Application for Plant Inventory. MSc Thesis, California State University.

Longley, P., Higgs, G., Martin, D., 1994: The Predictive use of GIS to model property valuations. International Journal of Geographical Information Systems, 8(2), 217-235.

Longley, P. A., Goodchild Michael, F., Maguire David, J., Rhind David, W. (Eds.), 2005: Geographical Information Systems: Principles, Techniques, Management and Applications, 2nd edition. Wiley, USA, 404 p.

Matney, J. A., Slocumb, W. S., Smith, J. W., Bonsall, P., Supak, S. K., 2019: Implementation and Evaluation of a Geospatial Management Solution for the U.S. National Park Service's Rivers, Trails, and Conservation Assistance Program. Journal of Park and Recreation Administration

Muñoz, L., Hausner, V. H., Monz, C. A., 2019: Advantages and limitations of using mobile apps for protected area monitoring and management. Soc. Nat. Resour., 32(4), 473-488.

Nedeljkovic, I., 2006: Image classification based on fuzzy logic. Remote Sens. Spatial Inform. Sci., 34, 1-6

Nowak, M. M., Dziób, D., Ludwisiak, L., Chmiel, J., 2020: Mobile GIS applications for environmental field surveys: A state of the art. Global Ecology and Conservation, 23.

Shcherbina, O., Shembelyeva, E., Trusins, J.: 2010. Spatial Development Decision Making and Modelling. Scientific Journal of RTU, 1, 25-31.

Soomro, T. R., Zheng, K., Pan, Y., 1999: HTML and multimedia web GIS, computational intelligence and multimedia applications. ICCIMA '99 Proceedings, Third International Conference, 371-382.

Tsou, M. -H., 2004: Integrated Mobile GIS and Wireless Internet Map Servers for Environmental Monitoring and Management. Cartography and Geographic Information Science, 31(3), 153-165.

Wyatt, P. J., 1997: The development of a GIS-based property information system for real estate valuation. International Journal of Geographical Information Science, 11(5), 435-450. 
Yang, Y., Sun Y., Li, S., Zhang, S., Wang, K., Hou, H., Xu, S., 2015: A GIS-Based Web Approach for Serving Land Price Information. ISPRS Int. J. Geo-Inf.., 4, 2078-2093.

Zadeh, L.A., 1965. Fuzzy sets. Inf. Control, 8, 338-353.

Zeng, T. Q. and Zhou, Q., 2001: Optimal spatial decision making using GIS: a prototype of a real estate geographical information system (REGIS). International Journal of Geographical Information Science, 15(4), 307-321.

Zivkovic, L. and Dordevic, A., 2016: Building a GIS Platform for Sustainable Land Management: A Case Study of the City of Cacak, Serbia. Journal of Urban Technology, 23(4), 29-46. 